\title{
DEI EX MACHINA: \\ a note on plural/mass indefinite determiners
}

\section{Roberto Zamparelli ${ }^{1}$}

\begin{abstract}
This article argues that the Italian plural indefinite article dei and its French counterpart is a partitive structure without an overt numeral. Unlike a similar proposal in (Chierchia 1998a), the present account crucially holds that the definite DP embedded in these 'defective partitives' is a kind-denoting DP. This assumption derives the lack of existence presupposition, the absence of cardinal numerals after $d e i$, the restrictions to certain types of DPs, the failure of $n e$-extraction and various other properties of this construction.
\end{abstract}

\section{Introduction}

Since the end of the nineties the structure and meaning of Romance plural/mass indefinite nominals has been a matter of some debate (Chierchia 1998a; Bosveld-De Smet 1998,2004,Storto 2003; Roy 2001). Meaningwise, the determiners that introduce these nominals, degli and des in (1), behave as plural or mass indefinite articles, equivalent to the English some in some people/water. Morphologically, however, degli and des appear to be composed of the preposition $d i$ "of" incorporated with the regular form of the definite article (il/lo/la/i/gli/le in Italian, le/la/les in French; I will henceforth use dei and des for the whole paradigm).

\footnotetext{
${ }^{0}$ Thanks to Alan Munn, Valentina Bianchi for comments and corrections. Special thanks to an anonymous reviewer for Studia Linguistica, whose comments almost exceeded the length of the paper. All remaining errors are of course my own.
} 
(1)

a. Ho incontrato [degli studenti].

Italian

I_have met [of_the students]

"I have met some students."

b. J' ai rencontré [des étudiants].

French

I have met [of_the students]

"I have met [some students]."

The process by which the definite article and a preposition combine into a preposizione articolata is completely standard in Italian and French. In particular, the combination di/de+Def-Art can be found in overt partitives, illustrated in (3) (Selkirk 1977, Hoeksema 1996).
a. Ho incontrato tre degli studenti.
I_have met three of_the students.
b. J'ai rencontré trois des étudiants.
I have met three of_the students.

The question addressed in this article is whether the similarity between (1) and (2) justifies deriving the former from the latter in a compositional fashion; whether-in other terms-(1) are "partitives without a number". The answer I will propose is partly positive, partly negative: I will argue that dei/des are compositionally derived via a complex structure akin to that of partitives, but that the 'partitive' semantics applies not to a normal definite nominal, but to a kind-denoting definite of the type studied in Zamparelli (2002). Specifically, I propose that the base of a plu$\mathrm{ral} / \mathrm{mass}$ indefinite like (3a) is not the definite we find in (3b) and which must refers to some unique or familiar set of dodos, but the one we see in (3c), which would be rendered in English by a bare plural.

(3) a. [Dei dodo] dormivano nella mia gabbia.

[of_the dodos] slept in my cage

"Some dodos slept in my cage" 
b. [I dodo] stanno dormendo nella gabbia.

[the dodos] are sleeping in_the cage

"the dodos are sleeping in my cage" (some specific ones).

c. [I dodo] si sono estinti

[the dodos] self are extinct

"Dodos have become extinct" (as a species)

The structure of the paper is as follows. In section 2 I present the view that dei/des-nominals are partitives. In section 3 some old and new problems for this proposal are reviewed. Section 4 gives reasons to preserve some aspects of a dei-raising analysis. Sections 5 and 6 give the core of my proposal, address the problems raised in 3 and 4 , and discuss the role of $d i$. Section 7 addresses the non availability of the construction with singular counts. 8 discusses other points related to economy of structure, and concludes.

\section{Chierchia's theory}

Considering the similarity between (1) and (2) Chierchia (1998a) proposes that the two constructions are structurally identical ((4) and (5)) and refers to the former as the bare partitive construction.
a. Dei folletti. of_the elves
b. $\left[\mathrm{DP}\left[\mathrm{D} \mathrm{D}^{0}\right]\left[_{\mathrm{NP}}\left[\mathrm{N}_{\mathrm{N}} 0_{[+ \text {part }}\right][\mathrm{PP}\right.\right.$ di [DP $\mathrm{i}$ folletti] $\left.\left.]\right]\right]$
c. [DP [D $\left.\operatorname{dei}_{j}\right]\left[{ }_{\mathrm{NP}}\left[\mathrm{N} t_{j}\right]\left[\mathrm{PP} t_{j}\left[\mathrm{DP} t_{j}\right.\right.\right.$ folletti]]]]
a. Alcuni dei folletti.
Some of_the elves
b. [DP [D alcuni] [NP $\left[{ }_{\mathrm{N}} 0_{[+ \text {part }}\right]$ [PP $_{\mathrm{PP}}$ di [DP i folletti] $\left.\left.]\right]\right]$ 
According to Chierchia, the only difference between bare and overt partitives is the lack of an overt numeral in the higher D position. In order to license this position, the complex definite article + preposition $d e+i$ moves to $\mathrm{D}$, the position occupied by the numeral $(5 \mathrm{~b})$ in overt partitives. In Chierchia's analysis " $0_{[+ \text {part }]}$ " is an empty relational noun which selects an obligatorily definite DP and is responsible for the partitive meaning (i.e. $0_{[+p a r t]}$ denotes $\lambda \mathrm{x} \lambda \mathrm{y}[\mathrm{y} \leq \mathrm{x}]$ ). The composition between $0_{[+ \text {part }}$ and the definite article gives (6a). In the next step, $d e+i$ raises to $\mathrm{D}$, and an existential type-shift takes place $(\lambda \mathrm{P} \lambda \mathrm{Q} \exists \mathrm{x}[\mathrm{P}(\mathrm{x}) \wedge \mathrm{Q}(\mathrm{x})]$ composes with the denotation of $d e+i)$. The result is a determiner-type denotation $(<<e t><<e t>t>)$ where the partitive meaning is embedded in the first term of the conjunction $(6 b))$.

$$
\begin{array}{ll}
\text { a. } & \llbracket 0_{[+ \text {part }]} \rrbracket \circ \llbracket \text { the } \rrbracket=\lambda \mathrm{R} \lambda \mathrm{x}[\mathrm{x} \leq \iota \mathrm{R}] \\
\text { b. } & \left.\llbracket\left[\mathrm{DP} \operatorname{dei}_{j}\right] \rrbracket=\lambda \mathrm{P} \lambda \mathrm{Q} \exists \mathrm{x}[\mathrm{P}(\mathrm{x}) \wedge \mathrm{Q}(\mathrm{x})]\right) \circ \lambda \mathrm{R} \lambda \mathrm{x}[\mathrm{x} \leq \iota \mathrm{R}]= \\
& \lambda \mathrm{P} \lambda \mathrm{Q} \exists \mathrm{x}[\mathrm{x} \leq \iota \mathrm{P}(\mathrm{x}) \wedge \mathrm{Q}(\mathrm{x})]
\end{array}
$$

As Chierchia points out, one syntactic advantage of this analysis is that it derives the impossibility of coordinating $d e i$ with other determiners. If $d e i$ was a plural numeral, we would expect it to appear in coordinations with a cardinal (7a), or with a vague cardinality adjective (7b), on the model of (8). Yet both possibilities are strongly ungrammatical.

a. *Una o delle persone.

One or of_the people.

b. *Molte o (solo) delle persone.

Many or (only) of_the people.
a. [uno o due] documenti [one or two] documents
b. [molti o pochi] documenti [many or few] documents 
If $d e i$ is derived from an internal DP and moved to a higher D position, the resulting structure would be either one where a head (D) is coordinated with a phrase, the DP containing the chain of $d e i(9 a)$, or one where the coordination applies to heads (9b), but dei has moved to the conjunct position from outside, in violation of the ATB-constraint. Either way, the result is excluded. ${ }^{2}$
a. *[DP [\&P [D una $]$ o [DP delle $i \ldots$ [DP $t_{i}$ persone $\left.\left.]\right]\right]$
b. *[DP [\&P [D una $]$ o [D delle $i]] t_{i}$ persone $]$

Raising the $d e+i$ complex to $\mathrm{D}$ and performing existential closure gives dei the scope possibilities of a full-fledged determiner. In particular, Italian dei can take scope over other operators, much as the English plural indefinite determiner some, and unlike bare plurals.
a. Non ho visto ragazzi. Not I_have seen boys "I haven't seen boys"

b. Non ho visto dei ragazzi. $\sqrt{ } \exists>\neg$ Not I_have seen of_the boys "I haven't seen some boys" or "There are boys I haven't seen"

Interestingly, even though the dei-nominal as a whole has an indefinite meaning, it cannot be used in negative existential statements: (11) cannot mean "Elves do not exist", only "Some elves are not present (in some spatio-temporal location)".

(11) Non ci sono dei folletti.

not there are of_the elves

“There aren't some elves"

According to Chierchia, this follows from the fact that—unlike a bare plural - the bare partitive in (10b) contains a $\iota$-operator, which triggers the existence presuppositions normally associated 
with definiteness. The conflict with existential statements is predicted by analyzes in which the internal noun phrase of a felicitous existential statement must not carry any presupposition of existence of its own (e.g. Zucchi 1995). Thus, the partitive analysis captures both the otherwise coincidental homophony between these indefinite articles and the partitive, and a peculiar aspect of their distribution.

A last advantage of Chierchia's analysis is that it correctly predicts the lack of $d e i$-indefinites in languages where a plural indefinite determiner is available. This follows from the assumption that if a language has an overt lexical item to obtain a given meaning it cannot resort to covert operators to obtain the same meaning (unless this move is independently motivated, see Chierchia $1998 \mathrm{~b}$ for a full discussion). A case in point is Spanish, which has a partitive very similar to the Italian one, but also a plural indefinite determiner, unos: as predicted, no dei construction exists in Spanish.

\section{Storto's criticism}

Storto (2003) raises various arguments against Chierchia's bare partitive analysis. One concerns cross-linguistic differences between plural/mass indefinite articles in Italian and French. Unlike Italian $d e i$, which can take either wide or narrow scope, French des must have narrowest scope, like Italian and English existentially interpreted bare plurals (12a) (see also Bosveld-De Smet 1998, 2004). In addition, in Italian dei-nominals have no particular syntactic restrictions, while French des-nominals do. According to Roy 2001 and Delfitto 1993, they cannot appear as preverbal subjects of unaccusative predicates (12b). 
a. Tout les visiteurs ont lu des journaux.

no $\exists>\forall$ reading all the visitors have read of_the newspapers

"All the visitors have read newspapers"

b. *?Des linguistes sont arrivés. of_the linguists are arrived

In Bosweld-de Smet (2004), however, the nature of the restriction seems to be essentially semantic: $d e s / d u$ forms are claimed to be impossible as subjects of individual-level predicates (13a), and to require a coda with certain stage-level predicates (13b).

a. *Des enfants sont très observateurs.

Of_the children are very observing

b. Des pas sont visibles ??(sur la neige).

Of-the steps are visible (in the snow)

Setting aside a discussion of the precise characterization of these restrictions, it is evident that without additional assumptions no common analysis can be given for the meaning and distribution of bare partitives in Italian and French.

A second and more serious challenge for Chierchia's analysis is that the $\iota$-operator embedded in his semantics for bare partitives makes predictions that are too strong. First, if the illformedness of (11) as a pure existential statement is due to presuppositions of existence associated with $d e i$, positive existential statements should be expected to be just as bad (much as ?? "there are the elves"), while they are perfectly fine.

(14) So che ci sono dei folletti e prima o poi ne troverò. I_know that there are of_the elves and sooner or later I will find them "I know elves exist, and sooner or later I'll find them"

Indeed, the same pattern is found even in English with the determiner some:

a. *There aren't some elves (any more). 
b. There are (still) some elves.

Storto concludes that the problem must lie in the negative polarity of these sentences, and suggest a connection with the fact that dei cannot be focused (see Storto 2003, sec. 4.3 ). Presuppositions of existence do not play any role in this explanation.

A second and more general issue is that Chierchia's analysis predicts synonymy between (16a) and (at least some reading of) (16b), modulo the semantic effect of $\mathrm{P}+\mathrm{D}$ raising to the upper D. (16b) is in fact like (16a), except for the overt presence of alcuni "some plur".

a. Dei folletti.

of_the elves.

"Some elves"

b. Alcuni dei folletti.

some of_the elves.

"Some of the elves"

Storto (2003) gives (17) (his example (10), see also his sec. 4.3) as a case where this synonymy does not obtain. (17a) is contradictory because the use of a full partitive presupposes the existence of a larger group of martians which have not landed. No contradiction arises in (17b), which carries no implicature that the group that landed is part of a (specific/definite) larger group. In other terms, (17a) obeys the constraint of proper partitivity, which dictates that a partitive must denote a plurality smaller that he one denoted by the definite it embeds (hence the oddness of two of my parents, one of my mother, see Barker 1998). In (17b) proper partitivity is not observed, and the relation expressed by $0_{+ \text {part }}$ reduces to equality. 
a. \#[Alcuni dei marziani che sono atterrati nel mio giardino $]_{i}$ mi hanno detto che [some of_the martians that are landed in my garden] $]_{i}$ told me that loro $_{i}$ sono gli ultimi della loro specie.

they $_{i}$ are the last of their species.

b. [Dei marziani che sono atterrati nel mio giardino $]_{i}$ mi hanno detto che loro $_{i}$ [of_the martians that are landed in my garden $]_{i}$ told me that they $y_{i}$ sono gli ultimi della loro specie.

are the last of their species.

"Some martians that have landed in my garden told me they are the last of their species"

An even sharper contrast comes from cases of generic quantification: (18a) is compatible with a situation in which some true Italians eat spaghetti but most do not; this is not true of (18b), which is a real generalization on what it takes, at least foodwise, to be a true Italian.

a. Alcuni dei veri italiani mangiano (sempre) gli spaghetti.

some of_the true Italians eat (always) the spaghetti.

"Some of the true Italians (always) eat spaghetti."

b. Dei veri italiani mangiano (sempre) gli spaghetti.

of_the true Italian eat (always) the spaghetti.

"True Italians (always) eat spaghetti"

To be sure, there are contexts in which the $\iota$-operator embedded in the bare partitive does seem to show up. In (19) dei and alcuni dei are fairly interchangeable (Chierchia, p.c.):

(19) Alla festa c' erano molti ragazzi e ragazze. Poi, \{alcuni dei ragazzi / At_the party there were many boys and girls. Then, \{ some of_the boys / dei ragazzi\} sono andati via.

of_the boys $\}$ have left.

Here dei ragazzi can mean "some of the boys that have just been mentioned". On further reflection, however, this possibility does not necessarily mean that dei embeds a definite DP, but 
simply that, like all other plural indefinites (and unlike the singular "a"), dei has a D-linked reading available. The first sentence above can in fact be continued with:

... $\{$ Molti / alcuni / tre $\}$ ragazzi se ne sono andati(, gli altri sono rimasti)

... \{many / some / three $\}$ boys have left(, the others have stayed)

where the indefinites can be interpreted as many/some/three of the boys there were. Obviously, this meaning cannot be due to the possibility that these indefinites embed a 'hidden' definite determiner.

Considering these facts, the presence of an $\iota$-operator in the semantics provided by the partitive analysis seems to be more of a hindrance than an advantage. The partitive account can stand only in conjunction with a principled account for why the definite inside the bare partitive is not generally "felt" to be there. Lacking such an account, Storto concludes that the uniform partitive analysis is not viable, that "bare partitives" are after all not partitives at all, and that Italian $d e i$ and French des, though perhaps diacronically derived from partitives, are now perceived as lexical determiners, with distinct scopal properties.

It seems to me that this solution throws away the baby with the bath water. Still unexplained is why, in various languages, a lexical indefinite determiner should have developed, ex-machina, from a defective partitive construction, or at least in the shape of a prepositional phrase. In addition, the Italian/French scope differences cannot be immediately derived. Last but not least, there are three reasons why dei/des cannot be reduced to a Romance equivalent of some, a nearsynonym of alcuni/quelques. First, unlike dei and the singular indefinite article, alcuni/some/quelques cannot be bound by generic operators or adverbs of quantification. Contrast (18)b with the English (21):

(21) $\quad$ Adolescents / an adolescent / $*$ some adolescent(s) $\}$ is/are $\{$ generally / often $\}$ tall. 
Second, unlike dei, some/alcuni/quelques cannot appear in predicate nominals such as (22). ${ }^{3}$

(22) Quei venti uomini sono $\{*$ alcune / delle $\}$ brave persone.

those 20 men are \{some / of_the $\}$ good people

Third and perhaps most importantly, dei differs from all other Italian indefinites, alcuni included, in not allowing the extraction of the clitic pro-NP ne (Belletti and Rizzi 1981, Zamparelli 1995,Ch.4), in many ways the analogous of English one-pronominalization. Starting from (23a), (24b) illustrates a well-formed ne-extraction from various types of indefinite determiners, while the sharply ill-formed (23c) contains our indefinite construction with dei, demonstratives, definites and normal partitives.

a. Conosco $\{$ alcuni / tre / molti / degli / questi / gli / tre degli $\}$ studenti I_know \{some / three / many / of_the / these / the / 3 of_the students francesi simpatici.

French nice

"I know some/three/many/these/the/three of the nice French students"

b. Di studenti francesi, ne ${ }_{i}$ conosco $\{$ alcuni/tre / molti $\} t_{i}$ simpatici. of students French, $\mathrm{CL}_{i}$ I_know \{some / three / many $\} t_{i}$ nice "French students, I know some/three/many nice ones"

c. *Di studenti francesi, ne $e_{i}$ conosco $\{$ dei / i / questi/tre dei $\} \quad t_{i}$ simpatici. of students French, $\mathrm{CL}_{i}$ I_know \{of_the / the / these / three of_the $t_{i}$ nice

The impossibility of extracting $n e$ from under $d e i$ is not dependent on a 'specific' reading of the dei-nominal. (24), for instance, is not out only as a question about some specific pieces of paper the hearer is seeking - a reading which would be pragmatically hard to get with any indefinite.

$$
\begin{aligned}
& \text { *Di pezzi di carta, ne cerchi dei puliti? } \\
& \text { of pieces of paper, } \mathrm{CL}_{i} \text { you_search of_the clean? } \\
& \text { "as for pieces of paper, are you looking for clean ones?" }
\end{aligned}
$$

It is also not possible to rule out (24) by appealing to the hypothesis that dei needs a noun to cliticize onto, unlike other indefinites but like the definite determiner. In (24) and (23b) ne-extraction 
has stranded a DP-internal adjective, as made clear by the glossae, and definite determiners can normally cliticize onto adjectives without any problem (witness $i$ simpatici ragazzi "the nice boys"). Moreover, if $d e i$ was a syncronically independent determiner it is not clear why the clitic property of the definite determiner should carry over to it.

Taken together, these points show that treating $d e i$ as an independent indefinite determiner leaves in the dark many aspects of its behavior. Let's therefore search further in the neighborhood of the partitive analysis.

\section{Advantages of a “dei/des"-raising analysis}

Chierchia's analysis can be factored in two parts: the idea that bare $d e i$-nominals are underlyingly partitives, and the idea that their external DP is licensed by raising the determiner and its associate $\mathrm{P}$ from the internal DP. Let's call a theory that adopts the second assumption a dei/des-raising analysis. I want to suggest that a dei/des-raising analysis is generally better suited than a purely lexical account to deal with the binding and predicative facts in (23) and (24). Consider how a possible analysis would run.

As we saw in (18), dei-nominals can be bound by a generic operator, but alcuni "some" cannot, regardless of the presence of a partitive.

(25) $\quad$ A Alcuni degli italiani / alcuni italiani $\}$ amano gli spaghetti. \{Some of_the Italians / some Italians\} like the spaghetti It cannot mean: "Generically speaking, Italians like spaghetti"

It seems reasonable to assume that operator-binding of $\mathrm{D}$ is possible only when this head position is not filled by some over lexical operator (which would preempt the external binder). Assuming a structure as in Chierchia's (4)b, suppose that when binding of $\mathrm{D}$ (a variable) is provided by an 
external adverbial dei is not interpreted in $\mathrm{D}$, but in NumP, the position immediately below $\mathrm{D}$ which hosts numerals.
a. [DP $\mathrm{D}^{e}\left[\mathrm{NumP} \operatorname{dei}_{i}\left[\mathrm{NP} t_{i}\left[\mathrm{PP} t_{i}\left[\mathrm{DP} t_{i}\right.\right.\right.\right.$ ragazzi $\left.\left.\left.]\right]\right]\right]$
LF: external binding possible
b. [DP [D $\left.\mathrm{dei}_{i}\right]\left[\mathrm{NP} t_{i}\left[\mathrm{PP} t_{i}\left[\mathrm{DP} t_{i}\right.\right.\right.$ ragazzi] $\left.\left.]\right]\right]$
LF: external binding impossible

Of course, it is quite possible, perhaps even plausible from a syntactic licensing standpoint, that all determiners must at some point be in $\mathrm{D}$ (or its Spec), either by being merged or by moving there. Assuming this as a working hypothesis, a semantic division emerges: determiners that reach D with a sufficiently 'rich' set of semantic features can be either interpreted in D or reconstructed in Num; those without the necessary features must be interpreted in Num; those merged in D must always be interpreted in D (no 'semantic lowering'). The determiners interpreted in D (or its Spec) include 'strong' quantifiers, in Milsark's sense, specific indefinites and proper names.

Suppose now that Italian dei can be interpreted in D or in Num, while English some is basegenerated in D. As a result, no adverbial binding of "some" obtains. ${ }^{4}$ If, as argued in Zamparelli (1995), predicate nominals are subparts of DPs which exclude the DP layer (e.g. bare NumPs), this captures the fact that some is not able to head predicate nominals:

\footnotetext{
a. Quei venti uomini sono [NumP delle $_{i} \ldots$ [DP $t_{i}$ brave persone $\left.]\right]=(22)$

b. *Those 20 men are [DP some good people]
}

The scope differences between French and Italian can now be approached along the same line, and tied to the well-known fact that while French does not have bare plurals, its des-nominals (particularly in the characterization given by Bosweld-de Smet 2004) closely match the meaning and distribution of English existentially interpreted bare plurals. 
In the system sketched above, French des-nominals can reach D and syntactically license the DP, but cannot be interpreted in this higher position, only in Num. Their existential meaning comes from existential closure (in the sense of Kratzer 1989, Diesing 1992), and is available only within a certain limited domain (Diesing's "VP"). Italian dei-nominals, on the other hand, can also be interpreted in $\mathrm{D}$, a difference probably linked to the fact that dei/des incorporate an inaudible nominal element: in French (a language where even vocatives require a definite determiner: bonjour les enfants!), nouns are not sufficient rich in $\phi$-features to allow an interpretation at D (Delfitto and Schroten 1992), while in Italian they are.

The last point, the impossibility of extracting $n e$ from under $d e i$, follows straightforwardly if the definite determiner that starts out at the edge of the lower DP in the structure (26) blocks an 'escape hatch' for NP-extraction (see Fiengo and Higginbotham 1981, Bowers 1988 for different incarnations of this idea). ${ }^{5}$ Despite their indefinite meaning, dei-nominals are once again aligned with real partitives:

(28) *Di studenti, ne ${ }_{i}$ conosco tre dei $t_{i}$ simpatici. of students, $\mathrm{CL}_{i}$ I_know three of the nice

Considering these facts, a dei/des analysis of the sort I just presented seems worth a deeper investigation. Of course, to make it viable, it is important to address and dismiss the problems listed in the previous sections, plus two serious syntactic pitfalls that Storto doesn't discuss.

First, in regular partitives the embedded definite DP may include numerals (29a). Yet, internal numerals are completely impossible in bare partitives (29b).
a. Alcuni dei dieci ragazzi. Some of_the ten boys.
b. *Dei dieci ragazzi. Of_the ten boys. 
(29b) would of course be expected if $d e i$ was an indefinite determiner, but then the data in (7) (the failure of $d e i$ to coordinate with any other determiner type, noted by Chierchia) would be unexpected.

Second, overt partitives can be built over null-nominal definite possessives such as $i$ loro 'theirs', lit. 'the their', $i$ miei 'mine', lit. 'the mine' (30a), but the corresponding bare partitives are impossible (30b). ${ }^{6}$
a. Tre dei miei valgono sei dei loro. 3 of_the mine are_worth 6 of_the their "Three of mine are worth six of theirs"
b. *Dei miei valgono dei loro. of_the mine are_worth of_the their

Both facts are utterly mysterious if bare partitives are simply partitives minus the number. In the next section I introduce the ingredients for a solution.

\section{Romance kind-denoting definites}

As is well known since Contreras (1986) and Casalegno (1987), Romance languages use plural or mass definites in sentences where English would use bare plural count or bare singular mass nominals with a "generic" or "kind" reading. The following are representative examples from Italian.

a. [I cani] si trovano un po' in tutte le taglie.

[the dogs] come a bit in all the sizes.

"Dogs come in all different sizes."

b. [I pitbull] sono impopolari in Inghilterra.

[the pitbulls] are unpopular in England

"Pitbulls are unpopular in England." 
c. [Gli uccelli] si sono evoluti da[i rettili].

[the birds] evolved from[the reptiles].

"Birds evolved from reptiles"

d. [L' elio] è abbondante nell' universo.

[The helium] is abundant in the universe

"Helium is abundant in the universe."

e. [I fisici nucleari] studiano [gli atomi].

[the physicists nuclear] study [the atoms].

"Nuclear physicists study atoms"

f. Pasteur scoprì [gli antibiotici].

Pasteur discovered [the antibiotics]

"Pasteur discovered antibiotics"

g. Il Quinto Giorno, a mezzogiorno spaccato, Dio creò [le zebre]. On the fifth day, at 12 o'clock sharp, God created [the zebras]. "On the fifth day, at 12 o'clock sharp, God created zebras".

Since Carlson (1977b), the predicates in (31) have been taken to select a kind sort in the argument(s) in brackets. Following Zamparelli (2002), I will assume that the Italian bracketed definites above denote "kinds of things", much as in Carlson's proposal for bare plurals in English.

My proposal is that the 'partitive determiner' dei/des is not a special indefinite determiner, but rather a Preposition+Determiner complex in a raising structure built on a kind-denoting definite. ${ }^{7}$ In first approximation, this means adopting the structure proposed in Chierchia (1998a), repeated below in (32), but with the internal definite DP denoting a kind (this structure will be slightly modified in the next section). Semantically, I propose that while the internal DP denotes a kind, outside the PP the denotation we are dealing with is simply an (intensional) set of objects, i.e. a regular plural common noun denotation.

$$
\text { [DP [D dei } \left.{ }_{j}\right]\left[\mathrm { NP } t _ { j } \left[\mathrm { PP } t _ { j } \left[\mathrm{DP} t_{j}\right.\right.\right. \text { folletti]]]] }
$$


The details of the semantic proposal will be given in Sec. 6. Informally, the composition of a bare partitive such as (33a) would be not (33b), but (33c).

a. Ho incontrato degli studenti. $=(1)$

b. "I met some of [the unique group of students in context]" Base: "Object" definite meaning

c. "I met some instances of [the student-kind]" Base: "Kind" definite meaning

Consider four immediate advantages of this proposal. First, it automatically explains why languages which do not express kinds using plural/mass definite DPs (e.g. English, German) do not have bare partitives either. This effect was captured in Chierchia's analysis by means of a complex set of assumptions about type-shifting and semantic typology (see the discussion around Chierchia's 1998a ex. (42)), which now become entirely superfluous.

Second, one notable property of Romance kind-denoting definites is that their extensional existence presuppositions are void. There is nothing contradictory or redundant in (34):

I fantasmi non ci sono, (mentre i vampiri esistono). the ghosts not there are, (while the vampires exist) "There aren't any ghosts, (but vampires exist)"

According to this statement, there are no instances of the ghost-kind in the current world/time (kinds must have realizations in some possible world, but not necessarily in the actual one). This automatically explains the vanishing existence presuppositions of dei-nominals noted by Storto.

The non-existence of a bare partitive with null-nominal possessives (e.g. dei loro seen in (30b)) follows from the fact that such DPs have a strong tendency to be normal object-level definites. Indeed, if we try to apply kind-selecting predicates (like be extinct, become widespread, etc.) to these DPs we get (at best) a subkind/taxonomic reading. For instance, assuming that 
professor Gilligan has spent his life studying dinosaurs, to say (35a) in reference to him means, if anything, (35c), not (35b).

a. (A proposito di dinosauri,) $[\mathrm{i} \quad$ suoi] $\mathrm{si}$ sono $\{$ estinti / diffusi $\}$ nel (speaking of dinosaurs,) [the his] have become $\{$ extinct / widespread $\}$ in_the tardo Cretacico late Cretacic

b. Dinosaurs ${ }_{i}$ became extinct/widespread in late Cretacic, and they ${ }_{i}$ have a salient relation with Gilligan.

c. The types of dinosaurs that have a salient relation with Gilligan became extinct/widespread in the late Cretacic.

In the subkind reading the common noun denotes a set of kinds, rather than a set of objects (see Carlson 1977a, Krifka et al. 1995, Krifka 1995, Zamparelli 1998). If the bare partitive is derived from the kind and not from the subkind or the object reading, the absence of dei suoi/loro as indefinites follows from the semantic restriction of (35a), to which I will return shortly.

The kind reading of Romance definites is also blocked if a numeral is inserted after the article (see Dayal 2000 for an account). For instance, even if there was a total of 3000 wolves on Earth, (36) can only be very odd statements about particular groups of wolves-the normal object-level interpretation of the definite is forced.

a. ??[ I tremila lupi ] si sono evoluti molto lentamente. [ the 3000 wolves ] evolved very slowly

b. ??[ I tremila lupi ] diventano più grandi come si viaggia verso nord. [ the 3000 wolves ] become bigger as one travels North

Now the impossible *dei 3000 lupi "of_the 3000 wolves" can no longer have the structure (37) (pre-movement), an obvious candidate if the internal DP was a normal definite. 


$$
*[\text { DP } \ldots . \text { [PP de [DP i } 3000 \text { lupi]]] }
$$

However, to exclude this case completely, we must make sure that the numeral cannot be located in the external DP, either, for if outside the PP we have a normal plural common noun denotation the numeral should be perfectly compatible with it. How can we rule out (38), with movement of $d e i$ to the higher $\mathrm{D}$ ? The answer here is that $d e+i$ would have to hop over the head position occupied by the numeral, in violation of the Head Movement Constraint (a case of Relativized Minimality).

$$
*\left[\mathrm{DP} \operatorname{dei}_{i} 3000\left[\mathrm{PP} t_{i}\left[\mathrm{DP} t_{i} \text { lupi] }\right]\right]\right]
$$

Notice, however, that if the upper DP contained elements which did not block the transit of $d e+i$ to D, a structure similar to (38) should in principle be allowed, and may in fact be quite useful to explain a serious potential objection to the kind-based analysis - the fact that there are other classes of definite nominals which cannot be interpreted as kinds but which do form the base for bare partitives. In (39) a kind reading for the definites is blocked by the presence of modifiers anchored to rigid designators, prenominal adjectival possessives and non restrictive adjectives (see Zamparelli 2002, sec. 4.3. Again, I am excluding the subkind/taxonomic interpretation). ${ }^{8}$

$$
\begin{aligned}
& \text { \{[I cani che erano qui ieri] / [ I miei cani }] /\left[\begin{array}{ll}
\text { simpatici cagnolini }]\} \\
\text { I }
\end{array}\right. \\
& \{[\text { the dogs that were here yesterday] / [the my dogs] / [the cute doggies] } \\
& \text { (??sono estinti/rari). } \\
& \text { ( are extinct) }
\end{aligned}
$$

The same definites can easily appear with dei (40). Notice that (40b) contrasts with the nullnominal cases discussed above (cf. *ho visto dei miei saltare il cancello, lit. 'I have seen of the mine jump the gate').

a. C' erano dei simpatici cagnolini. there were of_the nice doggies. 
b. Ho visto dei miei cani saltare il cancello.

I_have seen of_the my dogs jump the gate

c. Ho visto dei cani che erano qui ieri.

I_have seen of_the dogs that were here yesterday.

A first reaction to these data might be to retreat to the idea that "bare partitives" are ambiguous: they can embed either normal definites or kind-denoting definites. The latter would have no existence presuppositions, the former would. (40) would now be a case where the first option is forced. This optionality, however, is neither theoretically desirable nor empirically correct: it undermines the explanation for the absence of dei 3000 cani "of_the 3000 dogs", and *dei loro 'of_the theirs', which would now have a possible derivation. Moreover, the dei-nominals in (40), which are by hypothesis based on normal definites, should always carry presuppositions of extensional existence. This happens to be true for $(40 \mathrm{~b}, \mathrm{c})$, for independent reasons, ${ }^{9}$ but is definitely false for (40a).

Fortunately, the possibility of playing over two DP levels gives a clean way to accommodate these data. Unlike the numerals in (38), the adjectives and relatives in (40) are adjunct or specifiers; syntactically, there is no reason why they should block $d e+i$-raising to $\mathrm{D} .{ }^{10}$ In (41) these modifiers are attached outside the kind-denoting definite and restrict a set of ordinary objects derived from the kind:
a. $\quad\left[\mathrm{DP}_{1} \operatorname{dei}_{i} \operatorname{simpatici} \ldots\left[{ }_{\mathrm{PP}} t_{i}\left[\mathrm{DP}_{2} t_{i}\right.\right.\right.$ cagnolini $\left.]\right]$
b. $\quad\left[\mathrm{DP}_{1} \operatorname{dei}_{i}\right.$ miei $\ldots\left[{ }_{\mathrm{PP}} t_{i}\left[\mathrm{DP}_{2} t_{i}\right.\right.$ cani] $\left.]\right]$
c. $\quad\left[\mathrm{DP}_{1} \operatorname{dei}_{i}\left[{ }_{\mathrm{PP}} t_{i}\left[\mathrm{DP}_{2} t_{i}\right.\right.\right.$ cani $\left.]\right]$ che erano qui ieri $]$

Consider now the minimally different nominals in (42): 
E' difficile giudicare gli amici, ma ho conosciuto $\{\mathrm{i}$ loro / dei loro it is difficult to judge the friends, but I_have met \{the theirs / of_the their amici $/ *$ dei loro $\}$ e mi sembrano OK friends / of_the theirs \}, and they seem OK

Why isn't a structure like (41b) available for dei loro? The key is to observe that 'null-nominal' DPs must contain some kind of empty category, and that empty categories typically require licensing, by lexical selection or feature sharing with some independently licensed element. In this case, I suggest that the empty category is licensed by the possessive adjective and that to do so the possessor must be in the same DP. ${ }^{11}$ This is not a problem for normal definites and full partitives, but it blocks the kind reading needed for bare partitives.

Postulating a structure like (41) has another positive effect. As pointed out by an anonymous reviewer, in certain contexts $d e i$-nominals are more natural when they are modified in some way. The effect becomes particularly strong in the pre-verbal position of existential statements like (43). Interestingly, simple kind-denoting definites show, if anything, the opposite pattern (44).

a. ??Degli elfi non esistono. of_the elves don't exist

b. Degli elfi \{con la barba/con queste caratteristiche / che facciano Tai-Chi of_the elves \{with the beard / with these characteristics / that practice Tai-chi\} non esistono. don't exist

a. Gli elfi non esistono. the elves don't exist

b. Gli elfi \{?con la barba / ?con queste caratteristiche / ?che facciano Tai-Chi $\}$ the elves $\{$ with the beard/with these characteristics/that practice Tai-chi non esistono. don't exist 
The explanation for this difference is that here dei-nominals compete with kind-denoting definites. Since their structure is more complex, in the absence of modifiers (i.e. (43a), (44a)) the definites win. When modifiers are present, the possibility to use them with the kind definite, as in (44b), depends on how easily they can be conceptualized as 'natural classes' (how easy it is to think of elves that practice Tai-chi as a 'class' of elves). When this is not easily accomplished, the structure in (43b) becomes preferred, since here the modifiers can be interpreted outside the domain of the kind: among the individual object instances of the elf-kind we simply pick those with certain additional (and possibly quite random) properties.

The idea of a competition between structures with the same meaning but a different level of complexity can be used to shed some light on another issue, pointed out by an anonymous reviewer, i.e. what blocks the possibility to build a full partitive over a kind-denoting DP, with structure:

$$
\text { [DP } 3000\left[{ }_{\mathrm{PP}} \mathrm{de}+\mathrm{i}_{i}\left[\mathrm{DP}_{\text {kind }} t_{i}\right. \text { lupi]]]] }\right.
$$

This derivation would give us a regular partitive minus the existence/maximality presuppositions normally conveyed by the definite. But this meaning does of course exist: it is nothing more than the regular meaning of a numeral, applied to a common noun denotation within a single DP. An approach in terms of structural economy predicts that a structure like (45) will never be used.

A last, indirect piece of evidence for the kind-based derivation of the partitive determiner comes from examples which show the residual possibility of constructing existentials from kindbased demonstrative DPs:

a. Ha detto di quelle cose...!

He_has said of those things...

"He said such (amazing/terrible/disconcerting/...) things!" 
b. A quel punto, lui ha fatto di quelle smorfie... at that point, he has made of those faces

"At that point, he made such (ugly/bizarre/...) faces!"

Di quelle cose/smorfie behaves as an existential DP with an evaluative connotation. It means, roughly, that someone made faces or said things of a very special and extraordinary nature (exactly which nature can be clarified by the nominal or the context). Thus quelle cose/smorfie must refer to a kind here, a fact confirmed by the observation that the insertion of a numeral after the demonstrative simultaneously blocks the kind reading (exactly as in (36)) and the possibility for these PPs to appear as objects:

(47) *Ha fatto di quelle tre cose/smorfie (che conosci).

He_has said of those three things (that you_know).

In this case, it seems that the demonstrative and the preposition cannot form a single element and raise to license the upper $\mathrm{D}$ position. As a consequence, the distribution of these $d i+$ Demonstrative nominals is limited to those positions where the DP can be licensed externally, in the same way as a bare plural in Italian. In particular, the pre-verbal subject position is out (Longobardi 1994).
a. *Ricordo che [di quelle cose sono successe!] I_remember that [of those things are happened]
b. *Ho visto che [di quelle persone sono qui!]
I_have seen that [of those people are here]

\section{The nature of "di"}

Assuming that the internal $\mathrm{DP}_{2}$ denotes a kind, we turn to the role of $d i$. In Chierchia's account, $d i$ is meaningless, and the semantics comes mostly from a null partitive N. In the present account the partitive $\mathrm{N}$ is superfluous, so the semantic burden must be shifted back onto P. There are in fact other Italian examples where we see $d i$ with kind-denoting nominals (DPs such as a strange 
breed / a rare color), for instance the following predicational structures, where $d i$ is obligatory:

Fido era [??(di) \{una razza particolare / un colore strano\}]

Fido was (of) $\{$ a breed particular / a color strange $\}$

"Fido was (an animal) of a particular breed / a strange color"

One obvious approach is to say that the preposition that introduces dei-nominals $i s$ the lexical realization of the type/sort-shifter $\cup$, the "up" operator defined in Chierchia (1998b), which maps kinds into the set of their instantiations (a plural property).

$$
\llbracket[\text { of } \mathrm{DP}] \rrbracket=\cup \llbracket \mathrm{DP} \rrbracket=\{\mathrm{x} \mid \mathrm{x} \text { is an individual instantiation of } \llbracket \mathrm{DP} \rrbracket\}
$$

with $D P$

\section{kind-denoting}

Apart from the proliferation of $d i$-meanings which results, this idea is problematic with respect to the reasonable proposal that languages cannot employ hidden type-shifting operators if they have overt lexical elements with the same meaning (see Chierchia 1998b, Dayal 2000). If this view is on the right track, a di meaning ${ }^{\cup}$ would end up blocking the application of $\cup$ in all $d i$-less contexts-probably an incorrect prediction.

One alternative is to adopt the system in Zamparelli (1998), which tries to give a unified account of partitives and constructions like (49) above, and apply it to the case at issue. The basic idea of this system is the following (here I simplify the internal DP structure).

The di/of of partitives is an operator with two arguments, one in complement position and the other in specifier position. This operator, called R ("residue") returns the denotation of its specifier minus the denotation of its complement. The complement is a full DP; the specifier is filled by a copy of the NP embedded in the complement DP (or perhaps more correctly, of the projection for semantics plurality between D and NP, called PIP in Heycock and Zamparelli 2005). At spell-out, one of the copies of this NP (usually but not always the upper one) is not 
pronounced. This gives the following syntax and semantics:

a. $\quad\left[{ }_{\mathrm{RP}}[\mathrm{NP} \text { boys }]_{i}\left[\mathrm{R}^{\prime}\right.\right.$ of $\left[\mathrm{DP}\right.$ the $\left.\left.\left.[\mathrm{NP} \text { boys }]_{i}\right]\right]\right]$

b. $\quad \llbracket\left[\left[_{\mathrm{RP}}\right.\right.$ boys of the boys $] \rrbracket=\llbracket[\mathrm{NP} \text { boys }]_{i} \rrbracket-\left\{\llbracket\left[\right.\right.$ DP the $\left.\left.[\mathrm{NP} \text { boys }]_{i}\right] \rrbracket\right\}$

The NP boys denotes a set of plural boys (a join semi-lattice, containing all the possible pluralities that can be assembled with some number of boys in the domain, including the singularities but excluding the empty plurality). The definite the boys denotes the maximal element of the semilattice (i.e. the largest plurality of boys in the domain). The result of the subtraction is the set of all pluralities minus the largest one, which is the desired semantics for a partitive (see Barker 1998). This denotation is then fed to a numeral. Syntactically, this means that in partitives Num selects an RP which has acquired nominal features from the NP in its specifier; semantically, the cardinal in Num filters away any plurality which is incompatible with it. For example, with three individual boys $\mathbf{a}, \mathbf{b}$ and $\mathbf{c}$ in the domain, the derivation for two of the boys would be:
a. $\quad \llbracket b o y \rrbracket=\{a, b, c\}$
b. $\llbracket[$ [NP boys $] \rrbracket=\{\{a, b, c\},\{a, b\},\{b, c\},\{a, c\},\{a\},\{b\},\{c\}\}$
c. $\quad \llbracket\left[{ }_{D P}\right.$ the $\left[{ }_{N P}\right.$ boys $\left.]\right] \rrbracket=\operatorname{Max}\left(\llbracket\left[{ }_{N P}\right.\right.$ boys $\left.] \rrbracket\right)=\{a, b, c\}$ extracting the largest plurality as in Sharvy 1980
d. $\llbracket\left[{ }_{\mathrm{RP}}[\mathrm{NP}\right.$ boys $]\left[\mathrm{R}^{\prime}\right.$ of $[\mathrm{DP}$ the boys $\left.\left.]\right]\right] \rrbracket=\llbracket\left[{ }_{\mathrm{NP}}\right.$ boys $] \rrbracket-\left\{\llbracket\left[{ }_{\mathrm{DP}}\right.\right.$ the boys $\left.] \rrbracket\right\}=$ $\{\{a, b, c\},\{a, b\},\{b, c\},\{a, c\},\{a\},\{b\},\{c\}\}-\{\{a, b, c\}\}=$ $\{\{a, b\},\{b, c\},\{a, c\},\{a\},\{b\},\{c\}\}$ partitive denotation
e. $\llbracket\left[{ }_{N u m P} 2[R P\right.$ boys of the boys $\left.]\right] \rrbracket=\{\{a, b\},\{b, c\},\{a, c\}\}$
f. [DP $\mathrm{D}^{0} 2$ boys of the boys] Spell-out One 
This account derives various features of partitives. Their subtractive semantics obtains proper partitivity (see (53a)). Since the denotation of RP does not contain a supremum, the account derives the impossibility of (unmodified) partitives to be introduced by a definite article (53b). Next, partitives based on conjoined entity-denoting elements (names, pronouns or definites) are correctly excluded (53c), since no NP which can raise to [Spec,RP] in this case. For other aspects and details of the proposal, see Zamparelli (1998).
a. $\quad\{$ ??Two / One $\}$ of my two parents.
b. ??The 3 of the boys came.
c. ??One of $\{$ John, Jack and Mary / you and me / the boy and the girl $\}$

The question is now whether this system can be used to derive a plurality of objects from a kind-denoting definite. The answer depends in part on the semantic mapping of common nouns. Even for Carlson (1977b), bare plurals denotes kind entities only at the level we today call DP; below, the common noun denoted a property. This remains the mainstream view in recent work on this topic (e.g. Krifka 2003), supplemented with type/sort-shifting operators that obtain entitytype kind meaning from intensional plural properties, and vice-versa (respectively, the "down" $\cap$ and "up" $\cup$ operators in Chierchia 1998b). Over the last ten years, however, it has also be proposed that common nouns might directly denote kinds (see Zamparelli 1995, Krifka 1995, Longobardi 2002, 2005). In this case, the job of the definite article in kind-denoting Romance DPs would simply be that of letting the nominal denotation 'shine through' unmodified, a role most directly implemented in Longobardi's 1994 proposal that these articles are expletives and that the meaning of the DP is entirely determined by the kind-noun, possibly via LF-raising to D. 
For the purpose of the semantics of $d i$ as a residue operator, assigning a kind denotation to both specifier and complement would not produce a useful result: the set-complement operation would apply to kind entities, rather than to sets, and would thus be undefined (54). If the kind entity in Spec was type-shifted to a singleton property, set-complement would go through, but only to yield the empty set, again not a helpful restriction. ${ }^{12}$

$$
\llbracket\left[R P\left[N P_{k} \text { cani }\right]\left[R^{\prime} \text { di }\left[D P_{k} \text { i cani }\right]\right]\right] \rrbracket=\llbracket\left[N P_{k} \text { cani }\right] \rrbracket-\left\{\llbracket\left[D P_{k} \text { i cani }\right] \rrbracket\right\}=\operatorname{dog}^{k}-\left\{\mathbf{d o g}^{k}\right\}
$$

If however the NP denotes a plural property (here, a set of sets), we obtain the desired meaning, namely the denotation of the plural NP itself (noted $* \llbracket \mathrm{N} \rrbracket$ ). This is because the dog-kind is not a member of the set of pluralities of dogs, so the residue operation applies vacuously and the denotation of $[\mathrm{Spec}, \mathrm{RP}]$ is returned unmodified (55).

$$
\begin{aligned}
& \llbracket\left[R P\left[{ }_{N P} P_{<e t>t>} \text { cani }\right]\left[R^{\prime} \text { of }\left[D_{D P_{k}} \text { i cani }\right]\right]\right] \rrbracket=\llbracket\left[\left[_{N P_{<<t>t>}} \text { cani }\right] \rrbracket-\left\{\llbracket\left[\left[_{D P^{k}} \text { i cani }\right] \rrbracket\right\}=\right.\right. \\
& { }^{*} \mathbf{d o g} \boldsymbol{g}^{-}\left\{\operatorname{dog}^{k}\right\}={ }^{*} \mathbf{d o g},
\end{aligned}
$$

But how plausible is it to assume that even kind-denoting definite contain properties? Recall that the general strategy to decide whether a nominal has a kind or an object level denotation is to look at the predicates that can apply to it. Be extinct/widespread apply directly to kinds, but such predicates are a small minority. In most cases, the predicates that combine with kinds in characterizing sentences can be analyzed as applying to the objects that instantiate the kind, quantified over by a generic operator (GEN): this is indeed one of the main tenets of the quantificational theory of genericity in Gerstner and Krifka (1987), Krifka et al. (1995).

Now, complex kind-denoting DPs can incorporate the very same adjectives that are treated as object-denoting when they appear as predicates in characterizing sentences. Take (56a vs. b). 
a. [Gli insetti resistenti al DDT] si stanno diffondendo.

[the insect resistant to DDT] are becoming widespread

b. [Gli insetti che si stanno diffondendo] sono resistenti al DDT.

[the insect that are becoming widespread] are resistant to DDT

If resistenti al DDT must combine with an object (via GEN) in (56b), it is difficult to imagine that it could combine with a kind in (56a). It follows that the noun insetti in (a) must be a property, despite the fact that the bracketed DP as a whole denotes a kind. If insetti denoted a kind as well, we would need to compositionally derive the subkind insects that are resistant to DDT' by extracting instances from the insect-kind, applying to them the adjectival denotation, then rewrapping the result into a new kind:

$$
\cap\left[\lambda \mathrm{x}^{o} \in{ }^{\cup} \text { insects }^{\prime}: \text { resistant-to-DDT' }(\mathrm{x})\right]
$$

But if this "open and rewrap" trick can be performed any time a modifier attaches to the nominal, i.e. almost anywhere, the idea that nouns natively denote kinds becomes vacuous and essentially untestable. I conclude that properties of objects must be (natively or derivatively) available inside kind-denoting nominals, and that a derivation like (55) is thus viable. In what follows I will adopt this system; for consistency with the rest of the paper, I will continue to mark the Residue Phrase as PP.

\section{The problem of singular count nouns}

One remaining issue for a kind-based analysis of dei/des-nominals is why the application of $d i$ to other kind-denoting nominals doesn't give the same meaning or distribution as dei-nominals. For instance, the predicates we have seen in (49) above cannot appear in argument position. Contrast (58a) and (b): 
a. Fido è [della razza di cui parlavamo].

Fido is [of_the breed we talked about]

b. *A proposito di animali, ho visto [della razza di cui parlavamo] speaking of animals, I saw [of_the breed we talked about] it should mean: "...I saw one animal of the breed we talked about"

The solution, in this case, is likely to be in the syntax. Consider (59). The bracketed DP in (59a) can be an argument or a predicate. As a predicate, however, it can apply to kinds (59b), but not to objects (59c). To predicate of objects, the kind-final construction in (60a) must be used. Notice that the post-copular $\mathrm{N}$ (un cane) can be absent (60b), but it cannot appear after the kind-noun $(60 \mathrm{c})$.

(59) a. [La razza di cane/i di cui parlavamo] è questa. [the breed of $\operatorname{dog}(\mathrm{s})$ we talked about] è questa

b. Il chow-chow è [la razza di cane/i di cui parlavamo] the chow-chow is [the breed of $\operatorname{dog}(\mathrm{s})$ we talked about]

c. \#Fido è [la razza di cane/i di cui parlavamo] Fido is [the breed of $\operatorname{dog}(\mathrm{s})$ we talked about]

(60) a. Fido è un cane della razza di cui parlavamo. Fido is a dog of_the breed we talked about

b. Fido è della razza di cui parlavamo.

Fido is of_the breed we talked about

c. *Fido è della razza di cane/i di cui parlavamo. Fido is of_the breed of $\operatorname{dog}(\mathrm{s})$ we talked about

Zamparelli (1998) proposes that (60a) is derived from (59c) by fronting $d i$ and cane to the specifier and head of a Residue Phrase. Since moved elements cannot usually be spelled out twice, this explains why di cannot be repeated in (60c). If this is correct, (60b) must contain an empty category (a pro-NP) denoting a property of objects, moved to [Spec,RP] and probably from there 
to a higher specifier position within the DP.

(61) Fido è pro $_{j}$ di $_{i}+$ la razza $t_{i} t_{j}$ di cui parlavamo.

Fido is pro $_{j}$ of ${ }_{i}+$ the breed $t_{i} t_{j}$ we talked about

My suggestion is that the impossibility for [pro della razza] to be an argument comes from the licensing requirements of this predicative empty category in a fronted DP position. A similar constrains seems to be at work in (62) (from Bresnan 1973), when the predicative category too tall is fronted.
a. John is [a man too tall to serve].
b. [A man too tall to serve] can still be an asset.
c. John is [too tall a man to serve].
d. *[Too tall a man (to serve)] can still be an asset.

Another construction which appears to kind-denoting is the singular definite generic in brackets in (63a). Di cannot combine with it in any position: both argumental and predicative cases are completely out $(63 \mathrm{a}, \mathrm{c})$.

$$
\begin{aligned}
& \text { a. [Il leone] è il re della foresta. } \\
& \text { [the lion] is the king of_the forest } \\
& \text { b. *[Del leone] era il re della foresta. } \\
& \text { [of_the lion] was the king of_the forest } \\
& \text { c. *Simba era [del leone] } \\
& \text { Simba was [of_the lion] }
\end{aligned}
$$

This case can be excluded for the same reason that excludes normal singular count definites: for a singular definite to be successful, the context must have narrowed the property in the restrictor down to a singleton property. Thus, il leone 'the lion' is felicitous only if the NP leone denotes the property of being the unique salient lion in a context, say Simba'. Plugging this in a residue 
phrase we obtain the empty set.

(64) $[\mathrm{DP}[\mathrm{RP}[\mathrm{NP}$ leone $]$ di $[\mathrm{DP}$ il $[\mathrm{NP}$ leone $]]]]=\llbracket$ leone ${ }_{<e t>} \rrbracket-\{\llbracket$ il leone $\rrbracket\}=\left\{\right.$ Simba $\left.^{\prime}\right\}-$ $\left\{\operatorname{Simba}^{\prime}\right\}=\emptyset$

Generic cases such as (63) are open to the same analysis, provided their NP contains a singleton property like 'being a lion-kind', and not an object-level property (say, the set of all lions at the current world). Evidence for the first possibility (put forth in Dayal 2004 and in part in Zamparelli 1998) comes from the observation that the modifiers tolerated by the singular definite generic are a subset of those accepted by bare plurals of Romance plural definite generics (see Carlson 1977b:432). This suggests that these definites might not be decomposed into properties, or at least, not as easily as their plural counterparts.

Pulling together the discussion so far, we arrive at the following formulation for the DP dei ragazzi:

Syntactic Structure for Kind-based dei/des-nominals:

a. [ $\quad\left[\mathrm{PP}\right.$ di $\left[\mathrm{DP}_{2} \mathrm{i}[\mathrm{NP}\right.$ ragazzi]]]]]] Base

b. [ $\mathrm{PP}[\mathrm{NP}$ ragazzi $]\left[\mathrm{P}^{\prime} \mathrm{di}+\mathrm{i}\left[\mathrm{DP}_{2} \mathrm{i}\right.\right.$ ragazzi $\left.\left.\left.]\right]\right]\right] \quad$ Copying “ragazzi” and the article

c. $\left[\mathrm{DP}_{1}\right.$ dei $\left[\mathrm{NumP}\right.$ dei $\left[\mathrm{PP}[\mathrm{NP}\right.$ ragazzi $]\left[\mathrm{P}^{\prime}\right.$ dei $\left[\mathrm{DP}_{2}\right.$ + ragazzi $\left.\left.\left.]\right]\right]\right]$ Merging NumP, DP, moving dei and erasing intermediate copies for Spell-Out

One weakness the present account inherits from Chierchia's is the if $d e i$ and des are the result of movement of the definite determiner onto $\mathrm{P}$, one would expect, given the mirror principle, $* i+d i$, on a par with the German pronoun+preposition cases davor, lit. "that-from". Napoli and Nevis (1987) address this problem and conclude that dei and des are "agreeing forms" of the proposition di/de. Unfortunately, if this proposal means that $d e i$ is not a combination of $d i$ plus 
a definite but purely an inflected form of $d i$, this P-form seems to select bare plurals only, which is quite odd. If on the other hand it means that $d e i$ is indeed $d i+\mathrm{INFL+DEF}$, the question is why such agreeing forms should exist only in combination with definite determiners and why no forms like *duna (di+una "of+a") or *nogni (in+ogni "in+every") actually exist. My hunch is that the problem might be best approached with the tools of distributed morphology (Harley and Noyer 1999, Embick and Noyer 2001), but I have no contributions to give at this point. Note, however, that the solution of this problem is orthogonal to the issue of whether partitive determiners are compositionally derived from partitives: the possibility to incorporate the definite article with $\mathrm{P}$ is available in Italian for prepositions other than $d i$ (e.g. in "in", $s u$ "over", $d a$ "from"), yet in none of these cases can the resulting PP behave as a noun phrase.

\section{Conclusions}

The notions of 'economy' and 'blocking' have been invoked at various points in this paper. This might seem to be in bad taste, since if there is one domain where functional elements appear to have proliferated in the least economical of ways, this is the Italian existential indefinites. After all, all the forms listed in (66) are possible, and widely used.

Ho visto \{alcuni ragazzi / dei ragazzi / ragazzi / qualche ragazzo

I_have seen \{some boys / of_the boys / boys / some boy

If economy is to be preserved, we must conclude that bare plurals, bare partitives, alcuni "some", and qualche "some" (which despite its singular form is mostly plural in meaning, see Zamparelli 2004) do not compete with each other. This is not unreasonable: the meaning of the four objects is close, but not identical, given their distinct scopal and binding properties. Dei differs from alcuni and qualche in that it can be bound by generic operators (see (25)), and from the bare plural 
in the possibility to take wide scope and a 'specific' reading. Qualche has modal dimension, it easily spans plural and singular and in certain context has a strong tendency for narrow scope. Whatever their origin, these meaning differences must be what allows these forms to coexist side by side even in an economy-ruled language.

Which cases, then, are excluded by economy? One we have already considered is the possibility to build partitives with overt numerals over the kind denotation, which would give exactly the regular semantics of numerals with common nouns at the cost of an expanded structure. The next natural question is whether economy can block the inverse case, namely the possibility to build bare partitives over DPs that do not denote kinds. Another way to put the question is: if Chierchia's bare partitive analysis is, as I have argued, wrong, what makes it wrong?

Semantically, a bare partitive built on a regular plural definite would mean 'one or more of the boys', with a presupposition of existence and an anti-maximality entailment. Given that the singular meaning would probably be excluded via scalar implicatures due to the existence of the singular indefinite article, the meaning would probably be identical to alcuni dei ragazzi, which might be preferred on the basis of the idea that the overt determiner alcuni should block the invisible existential type-shift that accompanies dei raising. One could counter that unlike the alcuni-form, the dei-form can be bound by adverbs of quantification. But this is not so clear, given the fact that, by hypothesis, the definite article in this dei-form should be a 'real' definite, with existence presuppositions and all the contextual restrictions normally associated with definiteness. So, the question reduces to whether a normal partitive can be bound by adverbs of quantification in e.g.

(67) Three of the boys are always tall. 
Leaving the question unsettled, I conclude that there is at least a concrete possibility that the missing structure, $d i$ plus an object-level definite, is blocked from another overt form, partitives with alcuni. Of course, the absence of the Chierchia dei-structure could also be due to syntactic reasons, in particular the notion that the ability to license the upper empty $\mathrm{D}$ is specific to the form of definite article we find in kind-denoting definites, perhaps, if Longobardi (1994) is correct, for reasons linked to its 'expletive' status. I leave an exploration of this topic to future research.

To conclude, in this article I have proposed a compositional derivation for the plural/mass indefinite determiners in Italian and French. The main idea is that these forms are derived by applying a partitive operator to a definite which denotes an individual kind. The result of this operation is the set of individuals which instantiate the kind.

Combined with the idea that the des/dei-complex raises to the Num or D position of the upper DP, this analysis offers an account for the distribution and scope of dei/des-nominals in Italian and French, and for various features of the "definite" which appears to be embedded in these nominals. 


\section{Notes}

${ }^{1}$ DISCOF/CIMeC, Università di Trento, via Matteo del Ben 5b, 38100, Rovereto (TN), Italy Email: roberto.zamparelli@unitn.it

${ }^{2}$ If whether is generated in the $\mathrm{CP}$ area, the latter structure is analogous to *John knows whether and who $o_{i}$ John met $\mathrm{t}_{i}$.

${ }^{3}$ English some has a "modifier of amount/extent" reading (e.g. Those guys are quite some studs!) which is acceptable in predicative position. I take this meaning to be irrelevant here.

${ }^{4}$ Some evidence for a D position of plural some comes from the fact that while this determiner cannot be coordinated with numerals, as we have seen, it can appear in disjunctions with strong quantifiers such as most:

(68) We will buy some or (even) \{most / ??twenty $\}$ (of the) art pieces in this exhibit.

The fact that a some with the meaning 'approximately' can appear before plural numerals ("Some twenty people") points in the same direction.

${ }^{5}$ Notice that $d e i$ (unlike, e.g. demonstratives) does not block the extraction of the PP argument of relational nouns:

a. Di quali lingue conosci bene $\{$ dei / i $\}$ parlanti nativi? of which languages you_know well $\{o f$ the / the $\}$ speaker native? "of which languages do you know some native speakers"

b. un argomento di cui conosco dei veri esperti $t$
a topic
of which I_know of_the real experts $t$ 
"of topic of which I know some real experts"

A possible line of explanation is that the minimality restrictions introduced by the definite determiner are not triggered by the movement of an argumental PP (as opposed to NP). A second possibility rests on the intuition that the definite article of relational nouns is in some sense more 'indefinite' than the normal one (see the notion of 'weak definite' in Poesio 1994 and Zamparelli 1995, ch.5). Structurally, this 'relational the' would come from a DP position more internal than D, thus making the DP edge available for extractions. If this position is located within the projection targeted by the proform ne, relational the would not be possible in the case of $n e$-extractions, obtaining the contrast between (69) and (23)c. Unfortunately, for reasons of space I have to leave these suggestions unexplored.

${ }^{6}$ It is also worth observing that tre di loro ' 3 of them' does not have a corresponding indefinite $\mathrm{DP} *$ di loro, meaning 'some of them', and that tre di tutti i ragazzi '3 of all the boys', though marginal, is much better than *di tutti $i$ ragazzi, taken as a complete indefinite DP. These facts follow from the theory to be presented here, but they might also be attributed, in Chierchia's original analysis, to the fact that they do not contain the preposizione articolata de+DEF' which is taken to be a crucial ingredient for raising to the upper D. However, the existence of indefinite readings built with $d i$ plus a non-incorporated demonstrative, illustrated below in (46), shows that this explanation might not be the whole story.

${ }^{7}$ This idea was brought to my attention by Katia De Gennaro (pc); it is in fact not new (see in particular Renzi 1995, pg. 374), but I have never seen it analyzed in any detail. Alan Munn (pc) tells me that a similar proposal has been made for Japanese in Kakegawa (2000).

${ }^{8}$ More precisely, a definite with a non-restrictive adjective can be well-formed with a kind- 
denoting predicate if it can be interpreted as anaphoric to a kind which is contextually salient. The same is of course true in English: "Pitbulls $s_{i}$ are common nowadays ... [These dogs $]_{i}$ evolved from sausages.”. I take it that anaphoric links are unnecessary for genuine kind-denoting definites.

${ }^{9}$ The presuppositions come from the modifiers, not the article; cf. "a dog I met here yesterday", which does presuppose that dogs exist.

${ }^{10}$ The idea that adjectives are XPs which can be passed by N-raising is commonly adopted to explain the $N$ Adj order in Romance, see Cinque (1994), Longobardi (1994). In a head-internal analysis of relatives, the whole $\mathrm{PP}-\mathrm{DP}_{2}$ complex would have been moved from inside the relative.

${ }^{11}$ The $d i+\mathrm{PRON}$ form improves considerably in predicative position with a [+HUMAN,+MASC] interpretation:

$$
\begin{aligned}
& \text { ?Lui è dei miei/loro. } \\
& \text { he is of_the mine/their } \\
& \text { "he is one of my/their men" }
\end{aligned}
$$

I propose that these feature collectively help licensing the empty category, making a structure like (41)b possible.

${ }^{12}$ In a previous version of this article, circulated on the web, this was the route taken. The assumption was that the ill-formedness of (54) triggered an application of a $\cup$, obtaining a plural property denotation. It seems to me now that the existence of properties inside kind-denoting DPs is sufficiently well-motivated to grant a simplification of the system, as described below. 


\section{References}

Barker, C. (1998). Partitives, double genitive and anti-uniqueness. Natural Language and Linguistic Theory 16, 679-717.

Belletti, A. and L. Rizzi (1981). The syntax of ne: some theoretical implications. The Linguistic Review 1, 117-154.

Bosveld-De Smet, L. (1998). On Mass and Plural Quantification. The case of French des/du - NPs. Ph. D. thesis, University of Groningen.

Bosweld-de Smet, L. (2004). Toward a uniform characterization of noun phrases with "des" or "du". In F. Corblin and H. de Swart (Eds.), Handbook of French semantics. Stanford, CA: CSLI Publications.

Bowers, J. (1988). Extended X-bar theory, the ECP and the left branching condition. In Proceedings of WCCFL-7, Volume 7, pp. 46-62. Stanford Linguistics Association: Stanford University.

Bresnan, J. (1973). Syntax of the comparative construction in English. Linguistic Inquiry 4(3), $275-344$.

Carlson, G. (1977a). A unified analysis of the English bare plural. Linguistics and Philosophy $1,413-457$.

Carlson, G. and F. Pelletier (Eds.) (1995). The Generic Book. Chicago, IL: University of Chicago Press.

Carlson, G. N. (1977b). Reference to Kinds in English. Ph. D. thesis, University of Massachusetts at Amherst.

Casalegno, P. (1987). Sulla logica dei plurali. Teoria (2), 125-143. 
Chierchia, G. (1998a). Partitives, reference to kinds and semantic variation. In A. Lawson (Ed.), Proceedings of Semantics And Linguistic Theory, Volume VII, Ithaca, NY, pp. 7398. Cornell University: CLC Publications.

Chierchia, G. (1998b). Reference to kinds across languages. Natural Language Semantics 6, $339-405$.

Cinque, G. (1994). Partial N-movement in the Romance DP. In G. Cinque et al. (Eds.), Paths Towards Universal Grammar, pp. 85-110. Washington, D.C.: Georgetown University Press.

Contreras, H. (1986). Spanish bare NPs and the ECP. In I. Bordelois, H. Contreras, and K. Zagona (Eds.), Generative Studies in Spanish Syntax. Dordrecht: Foris.

Dayal, V. (2000). Number marking and (in)definiteness in kind terms. Ms., Rutgers University.

Dayal, V. (2004). Number marking and (in)definiteness in kind terms. Linguistics and Philosophy 27(4), 393-450.

Delfitto, D. (1993). A propos du statut lexical de l'article partitif en francais: Quelques hypothèses sur l'interaction entre morphologie et forme logique. In A. e. a. Hulk (Ed.), Du lexique à la morphologie: Du côté de chez Zwaan. Amsterdam: Rodopi.

Delfitto, D. and J. Schroten (1992). Bare plurals and the number affix in DP. Probus 3, 155185.

Diesing, M. (1992). Indefinites. Cambridge, Mass: MIT Press.

Embick, D. and R. Noyer (2001). Movement operations after syntax. Linguistic Inquiry 4(32), $555-595$.

Fiengo, R. and J. Higginbotham (1981). Opacity in np. Linguistic Analysis 7, 395-422. 
Gerstner, C. and M. Krifka (1987). Genericity, an introduction. Ms., Universität Tübingen.

Harley, H. and R. Noyer (1999). State-of-the-article: Distributed Morphology. GLOT 4(4), 3-9.

Heycock, C. and R. Zamparelli (2005). Friends and colleagues: Plurality, coordination, and the structure of DP. Natural Language Semantics 13, 201-270.

Hoeksema, J. (Ed.) (1996). Partitives: Studies on the syntax and semantics of partitive and related constructions. Berlin: Mouton de Gruyter.

Kakegawa, T. (2000). Noun phrase word order and definiteness in Japanese. In Proceedings of the 19th West Coast Conference of Formal Linguistics., pp. 246-259.

Kratzer, A. (1989). Stage and individual level predicates. In Papers on quantification. Department of Linguistics, UMass. Reprinted in Carlson and Pelletier (1995).

Krifka, M. (1995). Common nouns: a contrastive analysis of English and Chinese. In G. Carlson and F. Pelletier (Eds.), The Generic Book, pp. 398-411. Chicago, IL: University of Chicago Press.

Krifka, M. (2003). Bare NPs: Kind-referring, indefinites, both or neither? In Proceedings of Semantics and Linguistic Theory (SALT) 13, Cornell. CLC Publications.

Krifka, M. et al. (1995). Genericity: An introduction. See Carlson and Pelletier (1995), Chapter 1 , pp. 1-124.

Longobardi, G. (1994). Proper names and the theory of N-movement in syntax and logical form. Linguistic Inquiry 25, 609-665.

Longobardi, G. (2002). How comparative is semantics? a unified parametric theory of bare nouns and proper names. Natural Language Semantics 4(9), 335-369. 
Longobardi, G. (2005). Toward a unified grammar of reference. Zeitschrift für Sprachwissenschaft 24, 5-44.

Napoli, D. J. and J. Nevis (1987). Inflected prepositions in italian. Phonology Yearbook 4, 211-228.

Poesio, M. (1994). Weak definites. In Proceedings of SALT-4.

Renzi, L. (1995). L'articolo. In L. Renzi, G. Salvi, and A. Cardinaletti (Eds.), Grande grammatica Italiana di Consultazione, Volume I. Bologna: Il Mulino.

Roy, I. (2001). Weak des/du-NPs in French and judgement forms. Ms., USC.

Selkirk, E. (1977). Some remarks on noun phrase structure. In P. Culicover, T. Wasow, and A. Akmajan (Eds.), Formal Syntax, pp. 285-316. London: Academic Press.

Sharvy, R. (1980). A more general theory of definite descriptions. The Philosophical Review 89.4, 607-624.

Storto, G. (2003). On the status of the partitive determiner in Italian. In J. Quer, J. Schroten, M. Scorretti, P. Sleeman, and E. Verheugd (Eds.), Romance Languages and Linguistic Theory 2001; Selected Papers from Going Romance 2001, Amsterdam, pp. 315-330. John Benjamins Publishing Company.

Zamparelli, R. (1995). Layers in the Determiner Phrase. Ph. D. thesis, University of Rochester. (Published by Garland, 2000).

Zamparelli, R. (1998). A theory of Kinds, Partitives and of/Z Possessives. In A. Alexiadou and C. Wilder (Eds.), Possessors, Predicates and Movement in the Determiner Phrase, pp. 259-301. Amsterdam: John Benjamins.

Zamparelli, R. (2002). Definite and bare kind-denoting noun phrases. In C. Beyssade, R. Bok- 
Bennema, F. Drijkoningen, and P. Monachesi (Eds.), Romance Languages and Linguistic Theory 2000; selected papers from 'Going Romance' 2000, Utrecht, 30 November - 2 December, Volume 232 of Current Issues in Linguistic Theory, Amsterdam/Philadelphia, pp. 305-342. John Benjamins Publishing Company.

Zamparelli, R. (2004). On singular existential quantifiers in italian. Ms. Università di Bergamo, on-line at http://semanticsarchive.net/Archive/jZmMDViN/.

Zucchi, A. (1995). The ingredients of definiteness and the Definiteness Effect. Natural Language Semantics 3, 33-78. 